\title{
Targeting activated hepatic stellate cells (aHSCs) for liver fibrosis imaging
}

\author{
Dan Li ${ }^{1,2}$ (D) Li He ${ }^{1}$, Huizhuang Guo ${ }^{3}$, Hanwei Chen $^{3^{*}}$ and Hong Shan ${ }^{1,2,4^{*}}$
}

\begin{abstract}
Following injurious stimuli, quiescent hepatic stellate cells (qHSCs) transdifferentiate into activated HSCs (aHSCs). aHSCs play pivotal roles in the onset and progression of liver fibrosis. Therefore, molecular imaging of aHSCs in liver fibrosis will facilitate early diagnosis, prognosis prediction, and instruction and evaluation of aHSC-targeted treatment. To date, several receptors, such as integrin av $\beta 3$, mannose 6-phosphate/insulin-like growth factor II receptor (M6P/IGF-IIR), collagen type VI receptor (CVIR), platelet-derived growth factor receptor- $\beta$ (PDGFR- $\beta$ ), vimentin, and desmin, have been identified as biomarkers of aHSCs. Corresponding ligands to these receptors have also been developed. This review will discuss strategies for developing aHSC-targeted imaging in liver fibrosis.
\end{abstract}

Keywords: Molecular imaging, Activated hepatic stellate cells (aHSCs), Liver fibrosis, Biomarkers, Ligands

\section{Review}

\section{Introduction}

Liver fibrosis is a major public health problem and contributes to substantial morbidity and mortality. Iterative injury, abnormal wound healing processes, and redundant extracellular matrix (ECM) accumulation lead to liver fibrosis. Liver fibrosis can be divided into several stages according to the extent of fibrosis. Cirrhosis, an advanced stage of liver fibrosis, can cause many severe complications including portal hypertension, hepatic insufficiency, blood disorders, and hepatocellular carcinoma. Early diagnosis and precise staging of liver fibrosis are very important in managing the disease.

Although liver biopsy is regarded as the gold standard to evaluate liver fibrosis, it has several disadvantages including invasive nature, sampling error, inter/intra-observer variation in the pathological measurement, and the related complications [1, 2]. Multiple serum markers have been employed for liver fibrosis assessment but with limited sensitivity and specificity. Besides conventional imaging techniques, several new imaging techniques, including ultrasound-based transient elastography

\footnotetext{
*Correspondence: docterwei@sina.com; shanhong@mail.sysu.edu.cn ${ }^{3}$ Department of Radiology, Guangzhou Panyu Central Hospital, Guangzhou 511400, China

'Department of Radiology, The Third Affiliated Hospital of Sun Yat-sen University, Guangzhou 510630, China

Full list of author information is available at the end of the article
}

(TE) [3, 4], magnetic resonance (MR) elastography [5-7], acoustic radiation force impulse (ARFI) ultrasound imaging $[8,9]$, MR diffusion-weighted imaging (DWI) [10-12], T1 $\rho$ MR imaging [13-15], and MR perfusion-weighted imaging (PWI) $[16,17]$, have been applied to detect liver fibrosis. However, these techniques are usually based on morphological alterations of the liver and thus have difficulties to detect liver fibrosis at the early initiation stage or reflect the activity of liver fibrosis accurately. On the contrary, molecular imaging can provide the cellular or molecular information of a diseased liver, which will facilitate early diagnosis and accurate staging of liver fibrosis. In this review, we summarize recent studies on activated hepatic stellate cell (aHSC)-targeted imaging in liver fibrosis.

\section{Biological and pathological function of hepatic stellate cells}

Hepatic stellate cells (HSCs) are situated in the space of Disse, between hepatocytes and sinusoidal endothelial cells. They constitute $\sim 15 \%$ of the total liver resident cells [18] and account for $\sim 1.5 \%$ of the total liver volume. In normal liver, HSCs are in the quiescent state and play important roles in supporting liver development and regeneration, vitamin A storage, immunoregulation, liver hemodynamic homeostasis, etc. [19]. Following injurious stimuli, quiescent HSCs (qHSCs) transdifferentiate into aHSCs. HSC

\section{实 Springer}


activation consists of two main phases: initiation and perpetuation $[19,20]$. During the initiation phase, HSCs have gene and phenotype alteration to facilitate cellular response to a range of cytokines. After entering the perpetuation phase, HSCs are characterized by various changes in cell behavior, such as increase in the absolute cell number, ECM production, migration towards chemokines, contraction, loss of retinoid droplets, altered matrix degradation, and inflammatory signaling. aHSC quantity is clearly associated with fibrosis severity [21, 22]. Moreover, resolution of fibrosis is attributed to aHSC apoptosis [23], senescence [24], or their reversion to the quiescent state. Based on their important pathological role, aHSCs are essential targets for the diagnostic imaging of liver fibrosis (Fig. 1). Molecular imaging of aHSCs in liver fibrosis is expected to achieve the following objectives: (1) early diagnosis (aHSC detection before the pathological changes in the liver), (2) prognosis prediction (progression or regression), and (3) instruction and evaluation of aHSC-targeted treatment.

\section{Targets with imaging}

\section{Integrin av $\beta 3$}

Integrins are heterodimeric glycoprotein receptors formed by $\alpha$ and $\beta$ subunits. To date, 18 types of $\alpha$ subunits and 8 types of $\beta$ subunits have been recognized in mammals [25]. Different assemblies of the $\alpha$ and $\beta$ subunits result in 24 distinct integrins [26], and each type of integrin has a defined binding specificity and signal transduction pathway. Integrins are the major receptors that mediate cellular adhesion and reaction to the ECM and thus play essential roles in regulating cell migration, growth, division, survival, differentiation, and apoptosis. Dysfunction of integrins is found in various pathological processes. Among the integrin family, integrin $\alpha v \beta 3$ has been most thoroughly studied. It is highly expressed in both tumor cells [27] and activated endothelial cells [28-30] and regulates tumor progression, metastasis, and angiogenesis. Various ECM proteins like vitronectin, fibrinogen, and fibronectin interact with the integrin $\alpha v \beta 3$ via the arginine-glycine-aspartate (RGD) motif [31]. Based on this discovery, diverse RGD derivatives have been developed using many synthetic strategies including RGD-flanking amino acid residues (RGD4C, RGD10) [32, 33], cyclization (cRGDyK, cRGDfK) [34, 35], and N-methylation (cRGDf-N(Me)V) [36]. Several nucleic acid aptamers were also reported to specifically recognize integrin $\alpha v \beta 3$ [37-39]. Integrin $\alpha v \beta 3$-targeted imaging $[40,41]$ and therapy $[42,43]$ in tumor have been extensively studied using these RGD ligands.

Studies in liver fibrosis show that integrin $\alpha v \beta 3$ is upregulated on aHSCs [44-46] and promotes HSCs survival and proliferation [44]. In contrast, the expression level of integrin $\alpha \mathrm{v} \beta 3$ is low in qHSCs, hepatocytes, and other nonparenchymal cells [47]. Therefore, integrin $\alpha v \beta 3$ can serve as a novel target for molecular imaging of HSCs. Cyclic pentapeptides cRGDyK [34] and cRGDfK [35] are the
(A) Normal liver
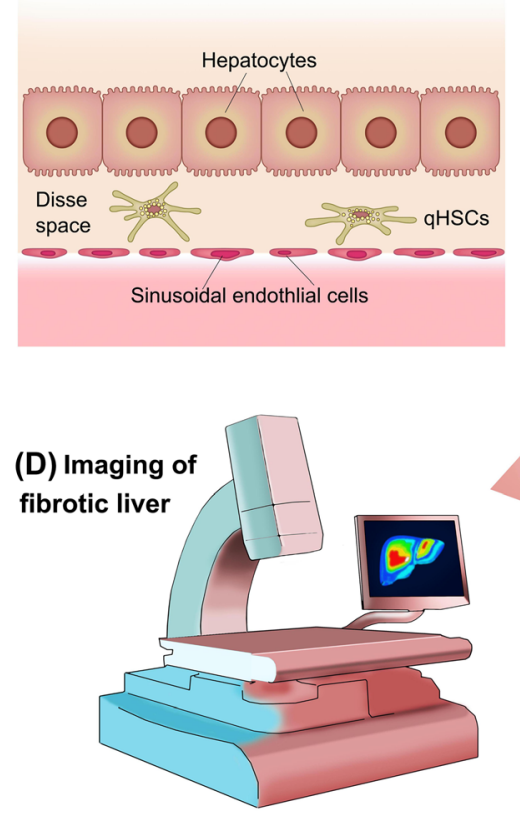

(B) Fibrotic liver

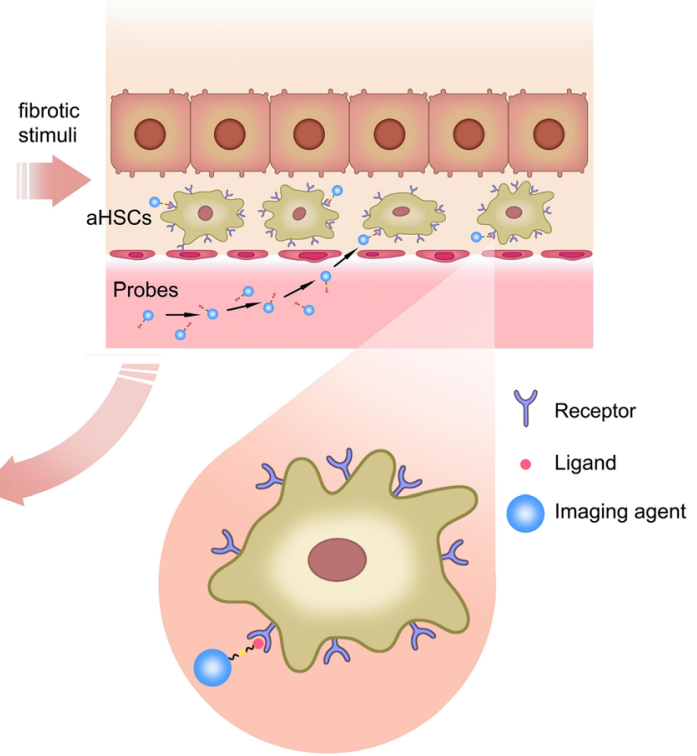

(C) Probes specifically bind to aHSCs

Fig. 1 Schematic diagram of activated hepatic stellate cell (aHSCs)-targeted imaging in liver fibrosis. a In normal liver, HSCs are in the quiescent state, i.e., quiescent HSCs (qHSCs). b Following fibrotic stimuli, qHSCs transdifferentiate into activated HSCs (aHSCs). Receptors that are specifically upregulated on aHSCs are potential targets for molecular imaging of liver fibrosis. c Magnified image that demonstrates imaging probes' specific binding to aHSCs. d Imaging of liver fibrosis 
most exploited for integrin $\alpha v \beta 3$ targeting. Cellular experiments demonstrated that cRGDfK was uptaken by aHSCs instead of qHSCs or hepatocytes [45]. ${ }^{125}$ I-cRGDfK-based historadioautography assay of rat hepatic sections showed that the hepatic relative densitometry was positively correlated with the severity of liver fibrosis [47]. Nuclear imaging, a highly sensitive technology, is widely used in both pre-clinical and clinical studies. ${ }^{99 \mathrm{~m}} \mathrm{Tc}$ is one of the most popular radionuclides because of its desirable nuclear properties $\left(t_{1 / 2}=6.02 \mathrm{~h}, E \gamma=140.51 \mathrm{keV}, I \gamma=89.06 \%\right)$, facile availability, and low cost. Li et al. [47] systemically investigated the potential of ${ }^{99 \mathrm{~m}}$ Tc-labeled cRGDfK for single-photon emission computed tomography (SPECT) imaging of HSC activity in fibrotic livers. ${ }^{99 \mathrm{~m}} \mathrm{Tc}$-cRGDfK was administrated through intravenous (i.v.) injection to assess the hepatic expression of integrin $\alpha v \beta 3$ in fibrotic (thioacetamide, TAA treatment) and control rats. At 45 min post injection (p.i.), the mean radioactivity ratio of the liver to heart (MRAR) could distinguish among rats with normal, mild fibrotic (TAA treatment for 3 weeks), or advanced fibrotic (TAA treatment for 9 weeks) liver (Fig. 2). ${ }^{99 \mathrm{~m}}$ Tc-cRGDfK uptake in fibrotic liver was blocked successfully through co-administration of cold cRGDfK, which confirmed the specificity of liver uptake. Small peptides are predominantly cleared via the kidney. Besides, integrin $\alpha v \beta 3$ is expressed on renal glomerular endothelial cells and, to a lesser extent, on tubular endothelial cells $[48,49]$. Therefore, kidney uptake of ${ }^{99 \mathrm{~m}} \mathrm{Tc}$ -

\section{(A)}

Control
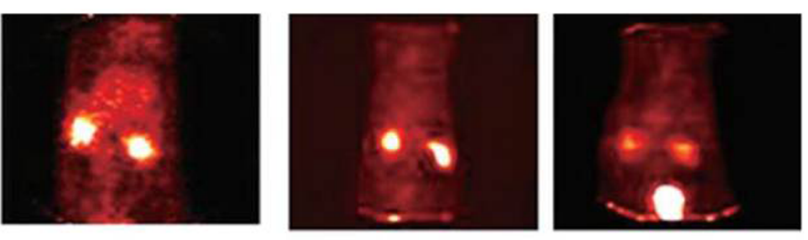

Mild fibrosis
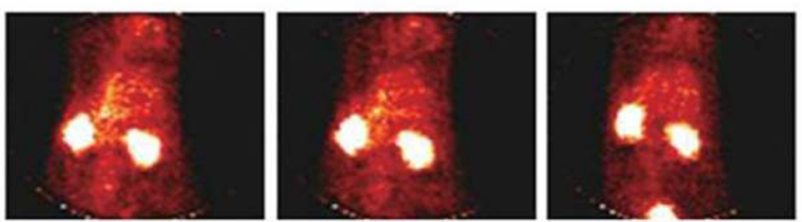

Advanced fibrosis
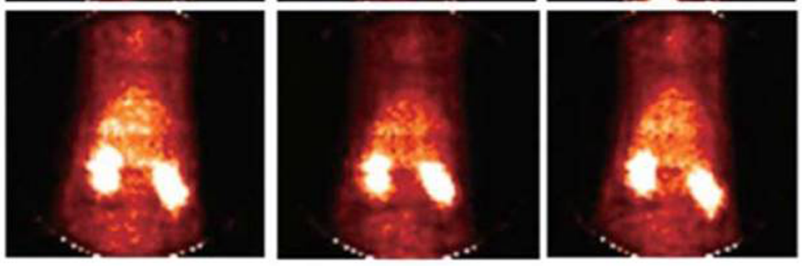

(B)

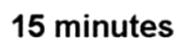

30 minutes

45 minutes

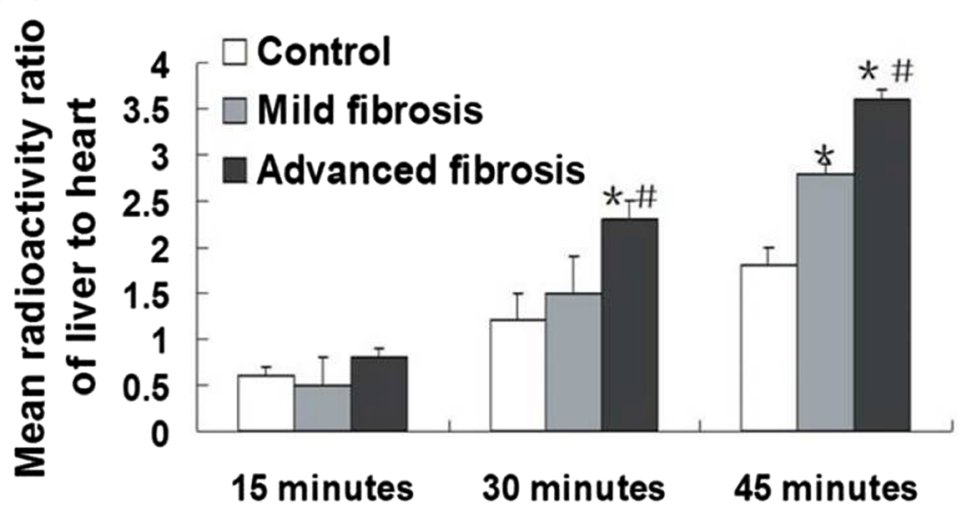

Fig. 2 Radionuclide images of the integrin av $\beta 3$ expression in the livers of the normal control and liver fibrosis rats. Mild and advanced fibroses were respectively induced in rats by thioacetamide (TAA) treatment for 3 and 9 weeks. Each animal was administered $6 \mu$ Ci of ${ }^{99 m}$ Tc-cRGDFK by way of the penile vein. a The representative radionuclide images were obtained at 15, 30, and 45 min after administration. b The region of interest (ROI) in the liver and heart was discriminated, and the radioactivity (counts/pixel) ratio of the liver to heart was calculated and compared. Data represent means \pm SD ( $n=3$ per group). ${ }^{*} P<0.05$ versus the control group, $\# P<0.05$ versus mild fibrosis. Reproduced with permission from ref. [47] 
cRGDfK was high. In this condition, radiotoxicity to the kidneys needs to be considered.

To improve integrin $\alpha v \beta 3$-targeted imaging, the binding avidity for integrin $\alpha v \beta 3$ has been maximized through the use of dimeric or multimeric cyclic RGD peptides [48, 50-52]. ${ }^{99 \mathrm{~m}} \mathrm{Tc}-3 \mathrm{PRGD} 2$ (3PRGD2 = PEG4E[PEG4-c(RGDfK)]2; PEG4 = 15-amino-4,7,10,13-tetraoxapentadecanoic acid) is one promising radiotracer [53-55]. The addition of PEG4 linkers increases the distance between the two RGD motifs and thus facilitates simultaneous binding to the neighboring integrin $\alpha v \beta 3$ [53]. ${ }^{99 \mathrm{~m}} \mathrm{Tc}-3 \mathrm{PRGD}_{2}$ shows fast excretion kinetics from the liver and kidneys [53, 54], which will lead to better lesion-to-background contrast. Moreover, ${ }^{99 \mathrm{~m}} \mathrm{Tc}-$ $3 \mathrm{PRGD}_{2}$ can be readily produced in high yield and purity from a kit formulation $[54,55]$. In clinical trials, ${ }^{99 \mathrm{~m}} \mathrm{Tc}-3 P R G D 2$ imaging is sensitive for cancer detection $[55,56]$. Zhang et al. further used ${ }^{99 \mathrm{~m}}$ Tc-3PRGD2 for a liver fibrosis study [57]. At $30 \mathrm{~min}$ p.i., the MRAR in rats with advanced liver fibrosis $(1.98 \pm 0.08)$ was significantly higher than that in control rats $(1.50 \pm 0.12)$. Also, the liver $t_{1 / 2}$ in the fibrosis group (27.07 \pm $10.69 \mathrm{~min}$ ) was significantly longer than that in the control group $(12.67 \pm 4.10 \mathrm{~min})$. However, the researchers did not study whether ${ }^{99 \mathrm{~m}} \mathrm{Tc}-3 \mathrm{PRGD} 2$ could be used for fibrosis staging. In both of the above two studies [47, 57], clinical SPECT machines were used for imaging; thus, the MRAR was relatively low and should be improved to attain precise diagnosis. Since ${ }^{99 \mathrm{~m}} \mathrm{Tc}$ 3PRGD2 has the potential for clinical translation, clinical trials in patients with liver fibrosis are also expected.

Magnetic resonance (MR) imaging produces images using magnetic fields and radio waves. It is absent of radiation and excellent at providing both anatomic and functional information. Both T1-positive (e.g., gadolinium chelates) and T2-negative (e.g., superparamagnetic iron oxide nanoparticles) contrast agents are used for MR imaging to boost up imaging sensitivity. Wang et al. conjugated cRGDyC with ultrasmall superparamagnetic iron oxide (USPIO) for aHSC-targeted MR imaging [46]. The preparation of the cRGDyC-USPIO probe includes three steps: synthesis of USPIO coated with oleic acid; surface coating with 1,2-distearoyl-sn-glycero-3-phosphoethanolamine- $N$-[carboxy(polyethylene glycol)-2000 (DSPE-PEG)] and 1,2-distearoyl-sn-glycero-3-phosphoethanolamine- $N$ [maleimide(polyethylene glycol)-2000 (DSPE-PEG-Mal)]; and $\mathrm{CRGDyC}$ conjugation to the nanoparticles. cRGDyCUSPIO was $13 \pm 3 \mathrm{~nm}$ in diameter. After administration of cRGDyC-USPIO or USPIO, MR imaging was performed in control rats and rats with early-staged liver fibrosis (CCl4 treatment for 3 weeks) using a clinical 1.5 Tesla (T) scanner. At $4 \mathrm{~h}$ p.i., liver T2 relaxation times of fibrosis rats treated with $\mathrm{cRGDyC}$-USPIO decreased significantly compared to those of normal rats with cRGDyC-USPIO, normal with USPIO, and fibrosis with USPIO (Fig. 3). Tissue assay confirmed that cRGDyC-USPIO could specifically target aHSCs. Iron oxide-based T2 imaging not only has the advantage of high sensitivity but also has two major disadvantages: negative contrast effects and artifacts caused by magnetic susceptibility [58]. On the contrary, paramagnetic material-based T1 imaging exerts a bright signal enhancement and has superior spatial resolution [59]. T1-T2 dual-modal MR imaging can combine the strength of each modality and thus offer more accurate information [60]. aHSC-targeted T1-T2 dual-modal MR imaging studies are expected in the future.

\section{Vimentin and desmin}

Both vimentin and desmin belong to the type III intermediate filament protein family and play important roles in maintaining the stability of cellular structure. Besides being distributed in the cytoplasm, these proteins are also recruited to the cell surface in pathological conditions [61-64]. During HSC activation, the expression of both vimentin and desmin is strongly upregulated [65]. $\mathrm{N}$-acetylglucosamine (GlcNAc) was identified as a specific glycoside ligand to vimentin and desmin and bound to the rod II domain of these proteins on plasma membrane surfaces [64]. Further study showed that GlcNAc-bearing polymers could bind to freshly isolated HSCs and suppressed cellular activation during in vitro culture [66]. In another study, GlcNAc was conjugated to indocyanine green (ICG) and polyethyleneimine (PEI)/TGF $\beta 1$ siRNA (PEI-D-GlcNAcICG/siRNA) for liver fibrosis imaging and therapy [67]. Optical imaging was carried out to monitor the distribution of the complexes (Fig. 4). At 1 day p.i., the complexes were retained in fibrotic livers, whereas they had been cleared out in normal livers. Moreover, more PEI-DGlcNAc-ICG/siRNA was distributed in fibrotic livers compared to the control complex that was absent of GlcNAc ligand. Tissue analysis showed that $79 \%$ of the PEI-D-GlcNAc-ICG/siRNA complex targeted to HSCs. In comparison, only $32 \%$ of the control complex targeted to HSCs. These results imply that GlcNAc could be a valid ligand for aHSC targeting. However, in the above study, imaging was performed at late time points ( 1 day). To facilitate clinical application, GlcNAc-based imaging is expected to be optimized for liver fibrosis detection at early time points after probe injection. In addition, the linear heptapeptide VNTANST was identified as a specific ligand that recognized vimentin on the cell surface [68].

\section{Targets without imaging (future work) \\ Mannose 6-phosphate/insulin-like growth factor II receptor (M6P/IGF-IIR)}

Mannose 6-phosphate/insulin-like growth factor II receptor (M6P/IGF-IIR) is a $300-\mathrm{kDa}$ single-chain 


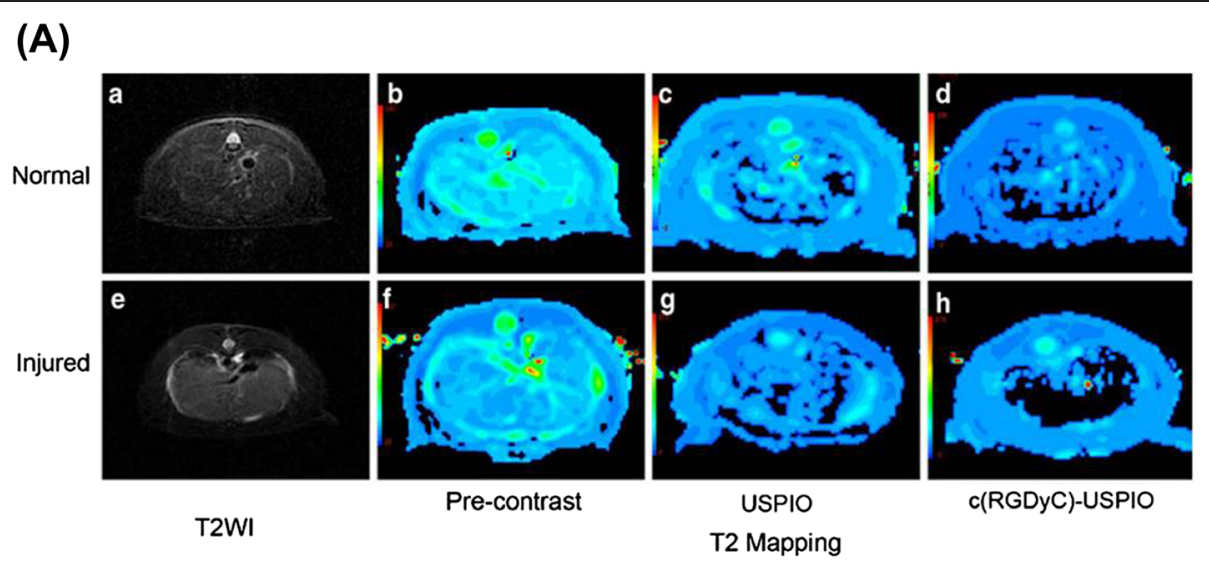

(B)

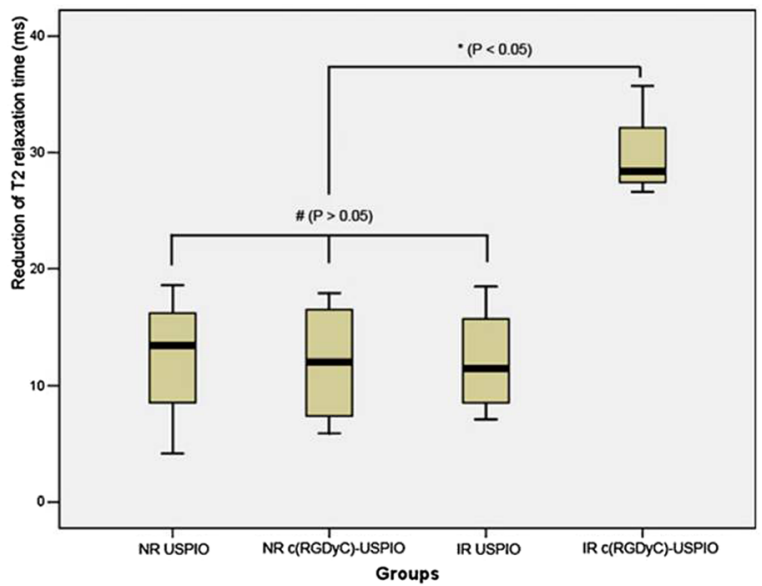

Fig. 3 MR images of the av $\beta 3$ integrin expression in the livers of the normal control and liver fibrosis rats. a MR imaging studies in normal rats (NR) and injured rat (IR, with early-staged liver fibrosis, CCI4 treatment for 3 weeks) after administration of USPIO or CRGDyC-USPIO. b The reduction of T2 relaxation times after the administration of USPIO or CRGDyC-USPIO in the normal and injured rat groups. Reproduced with permission from ref. [46]

transmembrane glycoprotein. Fifteen repeating domains constitute its large extracytoplasmic region. M6P/IGF-IIR binds to three types of ligands: IGF-II, the M6P-bearing proteins, and retinoic acid. One molecule of M6P/IGF-IIR binds one molecule of IGF-II and two molecules of M6P [69, 70]. IGF-II and M6P have their respective binding sites, but there is a mutual inhibition between these two ligands [71]. M6P/IGF-IIR carries out various functions, including lysosomal protein sorting and growth regulation. In normal liver, qHSCs express few M6P/IGF-IIR. But the receptor is upregulated on the plasma membrane of aHSCs during liver fibrosis [72, 73]. At the cell membrane, M6P/IGF-IIR can bind to transforming growth factor- $\beta$ (TGF- $\beta$ ) complex via M6P, convert latent TGF- $\beta$ into active TGF- $\beta[72,74]$, and thus promote fibrogenesis.

In 1999, Beljaars et al. took the lead to demonstrate that human serum albumin (HSA) modified with M6P could be taken up by aHSCs in fibrotic livers [75]. When 28 molecules of M6P were coupled to 1 molecule of HSA ( $\left.\mathrm{M} \mathrm{P}_{28}-\mathrm{HSA}\right)$, the hepatic accumulation increased to $59.2 \pm 9.2 \%$ in fibrotic rats and $\mathrm{M} \mathrm{P}_{28}$ - $\mathrm{HSA}$ was preferentially uptaken by aHSC. This drug carrier (M6PHSA) has been used to cargo therapeutic compounds to aHSCs in liver fibrosis [76-79], leading to enhanced drug efficacy and minimized drug toxicity. To date, M6P/IGF-IIR-targeted aHSC imaging has not been reported and thus is expected in the future. Besides, alternation of phosphate group in M6P with phosphonate, carboxylate, or malonate groups leads to improved binding affinity and stability [80-83]. These analogs could be used to facilitate aHSC targeting.

\section{Collagen type VI receptor (CVIR)}

Collagen type VI (CVI) is a heterotrimeric glycoprotein composed of three different $\alpha$ chains, $\alpha 1(\mathrm{VI}), \alpha 2(\mathrm{VI})$, and $\alpha 3(\mathrm{VI})$ [75]. $\alpha 3(\mathrm{VI})$ chains can be substituted by $\alpha 4(\mathrm{VI})$, $\alpha 5(\mathrm{VI})$, and $\alpha 6(\mathrm{VI})$ chains [84]. In cytoplasm, CVI monomers are assembled into dimmers and subsequently into tetramers. End-to-end alignment of secreted tetramers forms microfibrils in ECM [85]. CVI stimulates cell growth, promotes cell survival, and modulates matrix 
1days

(A)

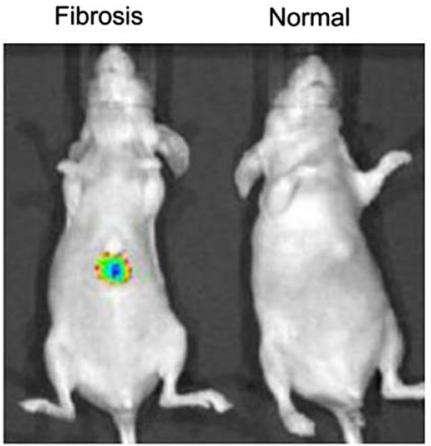

(B)

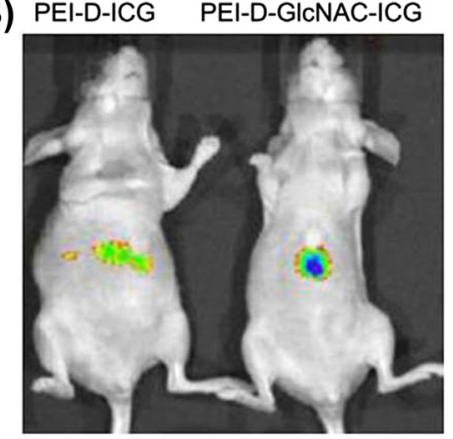

2 days

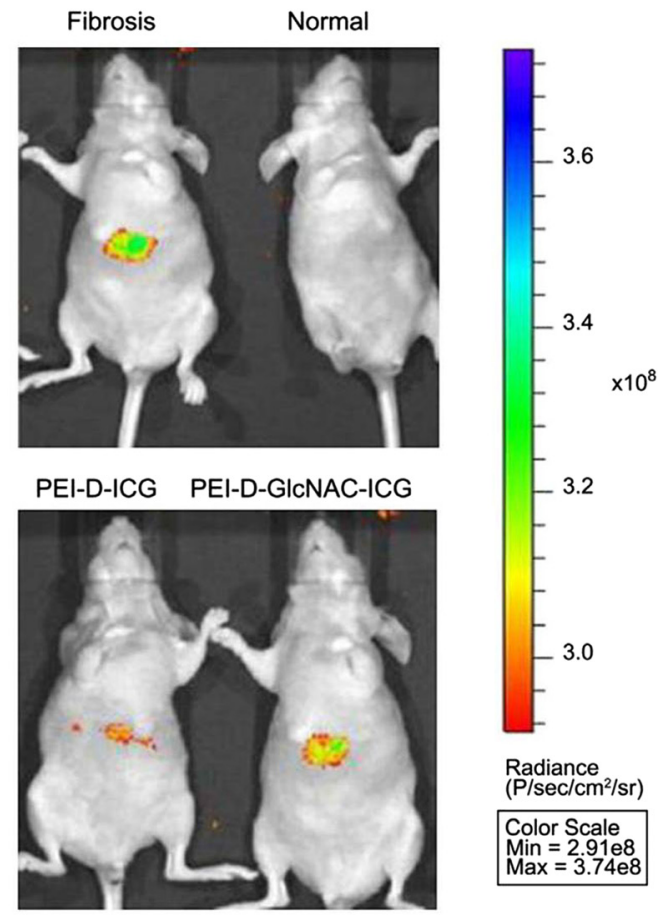

Fig. 4 Optical images of the vimentin and desmin expression in the livers of the normal control and liver fibrosis rats. Optical image of fibrotic and normal mice after administering PEI-D-GICNAC-ICG (a) and image of fibrotic mice after injection of PEI-D-ICG and PEI-D-GICNAC-ICG (b). Reproduced with permission from ref. [67]

homeostasis through interaction with cells and other matrix molecules [86]. HSCs are the major cells that produce CVI in the liver [87]. CVI is mainly distributed in the portal areas of normal livers. When liver fibrosis occurs, the accumulation of this type of collagen is enhanced, particularly in the fibrous septa $[88,89]$. CVI can bind to many types of receptors including integrins $\alpha 1 \beta 1, \alpha 2 \beta 1$, and $\alpha 1 \beta 1$ [90-92] and neuron/glia-type 2 (NG2) [93-95]. There are several RGD sequences in CVI, but the cyclic octapeptide C*GRGDSPC* selectively antagonizes the binding of CVI to cells [96]. The specific type of CVI receptor (CVIR) that mediates the attachment of this peptide to cells has not been defined.

HSA modified with $10 \mathrm{C}^{*}$ GRGDSPC ${ }^{*}$ moieties (pCVIHSA) was demonstrated as a carrier specifically targeting aHSCs [97]. Cellular experiments showed that aHSCs uptook much more pCVI-HSA compared to qHSCs. This implies that CVIR is upregulated on aHSCs. In fibrotic livers, aHSCs were the principal cells that bound the carrier. The cyclization of $C^{*}$ GRGDSPC* is accomplished via disulfide bond generation between two adjacent cysteine residues. A further modification was made to the peptide by substituting lysine for cysteine which resulted in $C^{*}$ GRGDSPK* $[98,99]$. The modified peptide is cyclized through an amide linkage between the cysteine and lysine residues and thus is more stable. This peptide was conjugated to liposomes for aHSC-targeted drug delivery in liver fibrosis [98, 99]. aHSC-targeted imaging based on this kind of peptide is anticipated in the future studies.

\section{Platelet-derived growth factor receptor- $\beta$ (PDGFR- $\beta$ )}

The platelet-derived growth factor (PDGF) is one of the most extensively investigated growth factors. In liver fibrosis, PDGF contributes to several behavior changes of HSCs in the process of activation, including proliferation, migration towards chemokines, and loss of retinoid droplets [100]. The PDGF family contains five dimeric members (PDGF-AA, PDGF-AB, PDGF-BB, PDGF-CC, and PDGF$\mathrm{DD})$ derived from four distinct polypeptide chains (PDGFA, PDGF-B, PDGF-C, PDGF-D) [100, 101]. PDGF-A and PDGF-B are secreted in an active form, whereas PDGF-C and PDGF-D demand extracellular proteolytic activation after being secreted. PDGF members exert their actions through binding to two different receptors, PDGF receptor PDGFR- $\alpha$ and PDGFR- $\beta$. PDGFR- $\alpha$ binds to PDGF-AA, PDGF-AB, PDGF-BB, and PDGF-CC, while PDGFR- $\beta$ binds to PDGF-BB and PDGF-DD [101]. In qHSCs, there is a constitutive expression of PDGFR- $\alpha$, whereas PDGFR- $\beta$ 
expression is not detected [102]. The expression level of PDGFR- $\beta$ is significantly increased on aHSC $[102,103]$.

Arginine-27 and isoleucine-30 in the PDGF-B chain are crucial for receptor binding [104]. Based on this work, Beljaars et al. designed a cyclic peptide (C*SRNLIDC*) that recognized PDGF receptors [105]. A targeted drug carrier was further produced through covalently linking 15 C"SRNLIDC* moieties to 1 HSA moiety (pPB-HSA) [105]. In vitro studies demonstrated that the cellular uptake of pPB-HSA in aHSCs was significantly higher than that in qHSCs. After i.v. injection, the majority of pPB-HSA was localized in aHSCs of fibrotic livers. C"SRNLIDC" has been applied to aHSC-targeted liver fibrosis therapy using HSA or liposomes as drug delivery vehicles [106-108]. The linear tridecapeptide ANFLVWEIVRKKP [109] and cyclic PDGF$\mathrm{BB}^{73-81}$ (R*KIEIVRKKC*) $[110,111]$ have also been identified as a PDGF-BB analog that recognized PDGF receptors. Although the PDGF-B chain is a ligand to both types of PDGFR, its asparagine-117 and leucine-119 are principally critical for PDGFR- $\beta$ binding [112]. Therefore, it is possible to design PDGF-BB analogs which exclusively bind to PDGFR- $\beta$. Besides, a PDGFR- $\beta$-specific RNA aptamer was reported recently [113]. Application of the above ligands to aHSC-targeted imaging remains to be investigated.

\section{Future prospects}

Several factors should be considered when designing imaging probes for aHSCs. First, the liver is regarded as the second most complex organ. Other cell types of the liver, such as Kupffer cells, sinusoidal endothelial cells, and hepatocytes, may nonspecifically uptake the probes. High molecular weight proteins, like serum albumin, are mainly metabolized by the liver. Although serum albumin-based carriers (M6P ${ }_{21}$-BSA, pCVI-HSA, pPBHSA) preferentially targeted HSCs in fibrotic livers, they were uptaken by endothelial cells [75, 97] or hepatocytes [105] in normal livers. Therefore, the accumulation level of these carriers in both fibrotic and normal livers was similar [75, 97, 105]. This characteristic makes these carriers suitable for HSC-targeted drug delivery rather than imaging. Low molecular weight ligands (such as peptides, aptamers), which are cleared mainly through the kidneys, will be more appropriate for this kind of imaging. Besides, the addition of PEG to probes could decrease the nonspecific uptake by Kupffer cells [46]. Second, novel MR techniques including MR elastography [5-7], MR DWI [10-12], T1 $\rho$ MR imaging [13-15], and MR PWI $[16,17]$ have emerged for detecting liver fibrosis. A combination of these techniques with aHSCtargeted MR imaging could provide abundant disease information on anatomical, functional, and molecular levels. Nuclear imaging techniques, including SPECT and positron emission tomography (PET), are often used for tumor imaging [114]. They not only have high sensitivity but also cause radio damage. Therefore, the pros and cons should be weighed before applying these techniques to liver fibrosis diagnosis. Third, ultrasound imaging has the advantages of high soft tissue contrast, low cost, and no radiation. Various kinds of bubbles have been developed as ultrasound contrast agents [115]. Among them, nano-sized bubbles, which can extravasate from blood vessels, are more suitable for imaging of extravascular cells. Thus, aHSC-targeted ultrasound imaging could potentially be accomplished through conjugating specific ligands to nanobubbles. Four, recent studies imply the bidirectional crosstalk between aHSCs and tumor cells [116, 117]. Tumor-derived factors activate HSCs, and in turn, aHSCs promote phenotypic changes, proliferation, and invasion of tumor

Table 1 aHSCs biomarkers and corresponding ligands (*aHSC-targeted imaging studies)

\begin{tabular}{|c|c|c|}
\hline Biomarker & Ligand & Reference \\
\hline \multirow[t]{12}{*}{ Integrin av $\beta 3$} & cRGDfK & {$\left[35,45,47^{*}, 57^{*}\right]$} \\
\hline & CRGDyC & {$\left[46^{*}\right]$} \\
\hline & RGD4C (ACDCRGDCFCG) & [32] \\
\hline & RGD10 (DGARYCRGDCFDG) & {$[33]$} \\
\hline & cRGDf-N(Me)V & [36] \\
\hline & Apt-avß3-1 & {$[37]$} \\
\hline & $\begin{array}{l}\text { (5'-GGGAGACAAGAAUAAACGC } \\
\text { UCAAUUCAACGCUGUGAAGGG } \\
\text { CUUAUACGAGCGGAUUACCCU } \\
\text { UCGACAGGAGGCUCACAAAAGGC-3') }\end{array}$ & \\
\hline & Apt-av $\beta 3-2$ & {$[38]$} \\
\hline & $\begin{array}{l}\text { (5'-UUCAACGCUGUGAAGGGCU } \\
\text { UAUACGAGCGGAUUACCC-3') }\end{array}$ & \\
\hline & Apt-av $\beta 3-3$ & {$[39]$} \\
\hline & $\begin{array}{l}\text { (5'- AGTTCGZZZZAAGAAAZZAG } \\
\text { CACACCGZZGACZZGZZZAGZG } \\
\text { GCGGACCA-3') }\end{array}$ & \\
\hline & $\begin{array}{l}\text { Z: 5-N-(benzylcarbox-yamide)-2'- } \\
\text { deoxyuridine }\end{array}$ & \\
\hline \multirow{2}{*}{$\begin{array}{l}\text { Vimentin and } \\
\text { desmin }\end{array}$} & N-acetylglucosamine (GlcNAc) & {$\left[64,66,67^{*}\right]$} \\
\hline & VNTANST & {$[68]$} \\
\hline \multirow[t]{2}{*}{ M6P/IGF-IIR } & M6P & {$[75]$} \\
\hline & $\begin{array}{l}\text { Phosphonate, carboxylate, or malonate } \\
\text { analogs of M6P }\end{array}$ & {$[80-83]$} \\
\hline \multirow[t]{2}{*}{ CVIR } & $C^{*} G_{R G D S P C}^{*}$ & {$[96,97]$} \\
\hline & $C^{*} G_{R G D S P K}^{*}$ & {$[98,99]$} \\
\hline \multirow[t]{6}{*}{ PDGFR- $\beta$} & $C^{*}$ SRNLIDC* & {$[105]$} \\
\hline & ANFLWWEIVRKKP & {$[109]$} \\
\hline & PDGF-BB ${ }^{73-81}$ & {$[110,111]$} \\
\hline & $\left(\mathrm{R}^{*}\right.$ KIEIVRKKC $\left.{ }^{*}\right)$ & \\
\hline & Apt-PDGFR- $\beta$ & [113] \\
\hline & $\begin{array}{l}\text { (5'-UGUCGUGGGGCAUCGAGUA } \\
\text { AAUGCAAUUCGACA-3') }\end{array}$ & \\
\hline
\end{tabular}


cells. Therefore, aHSC-targeted imaging in liver cancers could help better understand the pathophysiology of the tumor microenvironment and further instruct therapy.

\section{Conclusions}

HSC activation plays pivotal roles in the onset and progression of liver fibrosis. Receptors, such as integrin $\alpha v \beta 3$, M6P/IGF-IIR, CVIR, PDGFR- $\beta$, vimentin, and desmin, have been identified as biomarkers of aHSCs. Corresponding ligands to these receptors have also been developed (summarized in Table 1). Many studies focused on aHSC-targeted drug delivery for the treatment of liver fibrosis through taking advantage of these ligands. However, to our knowledge, only a few studies targeted aHSCs for in vivo imaging. To facilitate clinical translation, further studies are expected to optimize imaging probes for aHSCs.

\section{Ethical approval}

This article does not contain any studies with animals or human participants performed by any of the authors.

\section{Competing interests}

The authors declare that they have no conflict of interest.

\section{Authors' contributions}

All authors read and approved the final manuscript.

\section{Funding}

This work was funded by the National Natural Science Foundation of China (81430041, 81301266), 2016 Science \& Technology Nova Program of Pearl River of Guangzhou, 2014 Shan Hai Forum Cooperation Projects Foundation of Sun Yat-sen University, 2015 Distinguished Young Scholar Fund of The Third Affiliated Hospital of Sun Yat-sen University, and Medical key Subject Construction Project of Guangzhou (2013-2015).

\section{Author details}

'Department of Radiology, The Third Affiliated Hospital of Sun Yat-sen University, Guangzhou 510630, China. ${ }^{2}$ Guangdong Provincial Engineering Research Center of Molecular Imaging, Guangzhou 510630, China.

${ }^{3}$ Department of Radiology, Guangzhou Panyu Central Hospital, Guangzhou 511400, China. ${ }^{4}$ Interventional Radiology Institute of Sun Yat-sen University, Guangzhou 510630, China.

Received: 8 October 2015 Accepted: 27 November 2015

Published online: 09 December 2015

\section{References}

1. Regev A, Berho M, Jeffers $L$, Milikowski C, Molina EG, Pyrsopoulos NT, et al. Sampling error and intraobserver variation in liver biopsy in patients with chronic HCV infection. Am J Gastroenterol. 2002:97:2614-8.

2. Ratziu V, Charlotte F, Heurtier A, Gombert S, Giral P, Bruckert E, et al. Sampling variability of liver biopsy in nonalcoholic fatty liver disease. Gastroenterology. 2005;128:1898-906.

3. Vizzutti F, Arena U, Marra F, Pinzani M. Elastography for the non-invasive assessment of liver disease: limitations and future developments. Gut. 2009; 58:157-60.

4. Pinzani M, Vizzutti F, Arena U, Marra F. Technology insight: noninvasive assessment of liver fibrosis by biochemical scores and elastography. Nat Clin Pract Gastroenterol Hepatol. 2008;5:95-106.

5. Huwart L, Sempoux C, Vicaut E, Salameh N, Annet L, Danse E, et al. Magnetic resonance elastography for the noninvasive staging of liver fibrosis. Gastroenterology. 2008;135:32-40.

6. Wang Y, Ganger DR, Levitsky J, Sternick LA, McCarthy RJ, Chen ZE, et al. Assessment of chronic hepatitis and fibrosis: comparison of MR elastography and diffusion-weighted imaging. AJR Am J Roentgenol. 2011;196:553-61.

7. Wang $\mathrm{QB}$, Zhu H, Liu HL, Zhang B. Performance of magnetic resonance elastography and diffusion-weighted imaging for the staging of hepatic fibrosis: a meta-analysis. Hepatology. 2012;56:239-47.

8. Fahey BJ, Nightingale KR, Nelson RC, Palmeri ML, Trahey GE. Acoustic radiation force impulse imaging of the abdomen: demonstration of feasibility and utility. Ultrasound Med Biol. 2005;31:1185-98.

9. Friedrich-Rust M, Wunder K, Kriener S, Sotoudeh F, Richter S, Bojunga J, et al. Liver fibrosis in viral hepatitis: noninvasive assessment with acoustic radiation force impulse imaging versus transient elastography. Radiology. 2009;252:595-604.

10. Bakan AA, Inci E, Bakan S, Gokturk S, Cimilli T. Utility of diffusion-weighted imaging in the evaluation of liver fibrosis. Eur Radiol. 2012;22:682-7.

11. Luciani A, Vignaud A, Cavet M, Nhieu JT, Mallat A, Ruel L, et al. Liver cirrhosis: intravoxel incoherent motion MR imaging - pilot study. Radiology. 2008:249:891-9.

12. Taouli B, Tolia AJ, Losada M, Babb JS, Chan ES, Bannan MA, et al. Diffusionweighted MRI for quantification of liver fibrosis: preliminary experience. AJR Am J Roentgenol. 2007;189:799-806.

13. Allkemper T, Sagmeister F, Cicinnati V, Beckebaum S, Kooijman H, Kanthak $C$, et al. Evaluation of fibrotic liver disease with whole-liver T1rho MR imaging: a feasibility study at 1.5 T. Radiology. 2014;271:408-15.

14. Zhao F, Wang YX, Yuan J, Deng M, Wong HL, Chu ES, et al. MR T1 rho as an imaging biomarker for monitoring liver injury progression and regression: an experimental study in rats with carbon tetrachloride intoxication. Eur Radiol. 2012;22:1709-16.

15. Wang YX, Yuan J, Chu ES, Go MY, Huang H, Ahuja AT, et al. T1rho MR imaging is sensitive to evaluate liver fibrosis: an experimental study in a rat biliary duct ligation model. Radiology. 2011;259:712-9.

16. Hagiwara M, Rusinek H, Lee VS, Losada M, Bannan MA, Krinsky GA, et al. Advanced liver fibrosis: diagnosis with 3D whole-liver perfusion MR imaging -initial experience. Radiology. 2008;246:926-34.

17. Chen BB, Hsu CY, Yu CW, Wei SY, Kao JH, Lee HS, et al. Dynamic contrastenhanced magnetic resonance imaging with Gd-EOB-DTPA for the evaluation of liver fibrosis in chronic hepatitis patients. Eur Radiol. 2012;22:171-80.

18. Giampieri MP, Jezequel AM, Orlandi F. The lipocytes in normal human liver. A quantitative study. Digestion. 1981;22:165-9.

19. Friedman SL. Hepatic stellate cells: protean, multifunctional, and enigmatic cells of the liver. Physiol Rev. 2008:88:125-72.

20. Puche JE, Saiman Y, Friedman SL. Hepatic stellate cells and liver fibrosis. Compr Physiol. 2013;3:1473-92.

21. Ballardini G, Degli Esposti S, Bianchi FB, de Giorgi LB, Faccani A, Biolchini L, et al. Correlation between Ito cells and fibrogenesis in an experimental mode of hepatic fibrosis. A sequential stereological study. Liver. 1983;3:58-63.

22. Reeves HL, Burt AD, Wood S, Day CP. Hepatic stellate cell activation occurs in the absence of hepatitis in alcoholic liver disease and correlates with the severity of steatosis. J Hepatol. 1996;25:677-83.

23. Gonzalez SA, Fiel MI, Sauk J, Canchis PW, Liu RC, Chiriboga L, et al. Inverse association between hepatic stellate cell apoptosis and fibrosis in chronic hepatitis C virus infection. J Viral Hepat. 2009:16:141-8.

24. Krizhanovsky V, Yon M, Dickins RA, Hearn S, Simon J, Miething C, et al. Senescence of activated stellate cells limits liver fibrosis. Cell. 2008;134:657-67.

25. Humphries MJ. Integrin structure. Biochem Soc Trans. 2000;28:311-39.

26. Takada Y, Ye X, Simon S. The integrins. Genome Biol. 2007;8:215.

27. Desgrosellier JS, Cheresh DA. Integrins in cancer: biological implications and therapeutic opportunities. Nat Rev Cancer. 2010;10:9-22.

28. Hodivala-Dilke K. alphavbeta3 integrin and angiogenesis: a moody integrin in a changing environment. Curr Opin Cell Biol. 2008;20:514-9.

29. Cai W, Chen X. Anti-angiogenic cancer therapy based on integrin alphavbeta3 antagonism. Anticancer Agents Med Chem. 2006;6:407-28.

30. Brooks PC, Clark RA, Cheresh DA. Requirement of vascular integrin alpha v beta 3 for angiogenesis. Science. 1994;264:569-71.

31. Ruoslahti E, Pierschbacher MD. New perspectives in cell adhesion: RGD and integrins. Science. 1987;238:491-7.

32. Koivunen E, Wang B, Ruoslahti E. Phage libraries displaying cyclic peptides with different ring sizes: ligand specificities of the RGD-directed integrins. Biotechnology (N Y). 1995;13:265-70.

33. Holig P, Bach M, Volkel T, Nahde T, Hoffmann S, Muller R, et al. Novel RGD lipopeptides for the targeting of liposomes to integrin-expressing endothelial and melanoma cells. Protein Eng Des Sel. 2004;17:433-41. 
34. Aumailley M, Gurrath M, Muller G, Calvete J, Timpl R, Kessler H. Arg-Gly-Asp constrained within cyclic pentapeptides. Strong and selective inhibitors of cell adhesion to vitronectin and laminin fragment P1. FEBS Lett. 1991;291:50-4.

35. Haubner R, Gratias R, Diefenbach B, Goodman SL, Jonczyk A, Kessler H. Structural and functional aspects of RGD-containing cyclic pentapeptides as highly potent and selective integrin aVß3 antagonists. J Am Chem Soc. 1996;118:7461-72.

36. Dechantsreiter MA, Planker E, Matha B, Lohof E, Holzemann G, Jonczyk A, et al. N-Methylated cyclic RGD peptides as highly active and selective alpha(V)beta(3) integrin antagonists. J Med Chem. 1999;42:3033-40.

37. Mi J, Zhang X, Giangrande PH, McNamara 2nd JO, Nimjee SM, Sarraf-Yazdi $S$, et al. Targeted inhibition of alphavbeta3 integrin with an RNA aptamer impairs endothelial cell growth and survival. Biochem Biophys Res Commun. 2005;338:956-63.

38. Ruckman J, Gold L, Stephens A, Janjic N. Nucleic acid ligands to integrins. US7094535. 2006.

39. Lim EK, Kim B, Choi Y, Ro Y, Cho EJ, Lee JH, et al. Aptamer-conjugated magnetic nanoparticles enable efficient targeted detection of integrin alphavbeta3 via magnetic resonance imaging. J Biomed Mater Res A. 2014;102:49-59.

40. Zhang Y, Yang Y, Cai W. Multimodality imaging of integrin alpha(v)beta(3) expression. Theranostics. 2011;1:135-48.

41. Beer AJ, Kessler H, Wester HJ, Schwaiger M. PET imaging of integrin alphaVbeta3 expression. Theranostics. 2011;1:48-57.

42. Marelli UK, Rechenmacher F, Sobahi TR, Mas-Moruno C, Kessler H. Tumor targeting via integrin ligands. Front Oncol. 2013;3:222.

43. Chen $\mathrm{K}$, Chen $\mathrm{X}$. Integrin targeted delivery of chemotherapeutics. Theranostics. 2011;1:189-200.

44. Zhou X, Murphy FR, Gehdu N, Zhang J, Iredale JP, Benyon RC. Engagement of alphavbeta3 integrin regulates proliferation and apoptosis of hepatic stellate cells. J Biol Chem. 2004;279:23996-4006.

45. Huang XW, Wang JY, Li F, Song ZJ, Xie C, Lu WY. Biochemical characterization of the binding of cyclic RGDyK to hepatic stellate cells. Biochem Pharmacol. 2010;80:136-43.

46. Wang QB, Han Y, Jiang TT, Chai WM, Chen KM, Liu BY, et al. MR imaging of activated hepatic stellate cells in liver injured by CCI(4) of rats with integrintargeted ultrasmall superparamagnetic iron oxide. Eur Radiol. 2011;21:1016-25.

47. Li F, Song Z, Li Q, Wu J, Wang J, Xie C, et al. Molecular imaging of hepatic stellate cell activity by visualization of hepatic integrin alphavbeta3 expression with SPECT in rat. Hepatology. 2011;54:1020-30.

48. Li ZB, Cai W, Cao Q, Chen K, Wu Z, He L, et al. (64)Cu-labeled tetrameric and octameric RGD peptides for small-animal PET of tumor alpha(v)beta(3) integrin expression. J Nucl Med. 2007;48:1162-71.

49. Hamerski DA, Santoro SA. Integrins and the kidney: biology and pathobiology. Curr Opin Nephrol Hypertens. 1999;8:9-14.

50. Wu Y, Zhang X, Xiong Z, Cheng Z, Fisher DR, Liu S, et al. microPET imaging of glioma integrin \{alpha\}v\{beta\}3 expression using (64)Cu-labeled tetrameric RGD peptide. J Nucl Med. 2005;46:1707-18.

51. Liu S. Radiolabeled cyclic RGD peptides as integrin alpha(v)beta(3)-targeted radiotracers: maximizing binding affinity via bivalency. Bioconjug Chem. 2009;20:2199-213.

52. Liu S, Li D, Huang CW, Yap LP, Park R, Shan H, et al. The efficient synthesis and biological evaluation of novel bi-functionalized sarcophagine for (64)cu radiopharmaceuticals. Theranostics. 2012;2:589-96.

53. Wang L, Shi J, Kim YS, Zhai S, Jia B, Zhao H, et al. Improving tumor-targeting capability and pharmacokinetics of $(99 \mathrm{~m})$ Tc-labeled cyclic RGD dimers with PEG(4) linkers. Mol Pharm. 2009;6:231-45.

54. Jia B, Liu Z, Zhu Z, Shi J, Jin X, Zhao H, et al. Blood clearance kinetics, biodistribution, and radiation dosimetry of a kit-formulated integrin alphavbeta3-selective radiotracer 99mTc-3PRGD 2 in non-human primates. Mol Imaging Biol. 2011;13:730-6.

55. Ma Q, Ji B, Jia B, Gao S, Ji T, Wang X, et al. Differential diagnosis of solitary pulmonary nodules using (9)(9)mTc-3P(4)-RGD(2) scintigraphy. Eur J Nucl Med Mol Imaging. 2011;38:2145-52.

56. Zhu Z, Miao W, Li Q, Dai H, Ma Q, Wang F, et al. 99mTc-3PRGD2 for integrin receptor imaging of lung cancer: a multicenter study. J Nucl Med. 2012;53:716-22.

57. Zhang $X$, Xin J, Shi Y, Xu W, Yu S, Yang Z, et al. Assessing activation of hepatic stellate cells by $(99 \mathrm{~m}) \mathrm{Tc}-3 \mathrm{PRGD} 2$ scintigraphy targeting integrin alphavbeta3: a feasibility study. Nucl Med Biol. 2015;42:250-5.

58. Na HB, Song IC, Hyeon T. Inorganic nanoparticles for MRI contrast agents. Adv Mater. 2009;21:2133-48.
59. Caravan P, Ellison JJ, McMurry TJ, Lauffer RB. Gadolinium(III) chelates as MR contrast agents: structure, dynamics, and applications. Chem Rev. 1999;99: 2293-352.

60. Zhou Z, Huang D, Bao J, Chen Q, Liu G, Chen Z, et al. A synergistically enhanced T(1)-T(2) dual-modal contrast agent. Adv Mater. 2012;24:6223-8.

61. Huet D, Bagot M, Loyaux D, Capdevielle J, Conraux L, Ferrara P, et al. SC5 $\mathrm{mAb}$ represents a unique tool for the detection of extracellular vimentin as a specific marker of Sezary cells. J Immunol. 2006;176:652-9.

62. Bhattacharya R, Gonzalez AM, Debiase PJ, Trejo HE, Goldman RD, Flitney FW, et al. Recruitment of vimentin to the cell surface by beta3 integrin and plectin mediates adhesion strength. J Cell Sci. 2009;122:1390-400.

63. Creighton CJ, Li X, Landis M, Dixon JM, Neumeister VM, Sjolund A, et al. Residual breast cancers after conventional therapy display mesenchymal as well as tumor-initiating features. Proc Natl Acad Sci U S A. 2009;106:13820-5.

64. Ise H, Kobayashi S, Goto M, Sato T, Kawakubo M, Takahashi M, et al. Vimentin and desmin possess GlcNAc-binding lectin-like properties on cell surfaces. Glycobiology. 2010;20:843-64.

65. Niki T, Pekny M, Hellemans K, Bleser PD, Berg KV, Vaeyens F, et al. Class VI intermediate filament protein nestin is induced during activation of rat hepatic stellate cells. Hepatology. 1999;29:520-7.

66. Kim SJ, Ise H, Goto M, Akaike T. Interactions of vimentin- or desmin-expressing liver cells with N-acetylglucosamine-bearing polymers. Biomaterials. 2012;33: 2154-64.

67. Kim SJ, Ise H, Kim E, Goto M, Akaike T, Chung BH. Imaging and therapy of liver fibrosis using bioreducible polyethylenimine/siRNA complexes conjugated with $\mathrm{N}$-acetylglucosamine as a targeting moiety. Biomaterials. 2013;34:6504-14

68. Cutrera J, Dibra D, Xia X, Hasan A, Reed S, Li S. Discovery of a linear peptide for improving tumor targeting of gene products and treatment of distal tumors by IL-12 gene therapy. Mol Ther. 2011;19:1468-77.

69. Tong PY, Gregory W, Kornfeld S. Ligand interactions of the cation-independent mannose 6-phosphate receptor. The stoichiometry of mannose 6-phosphate binding. J Biol Chem. 1989;264:7962-9.

70. Tong PY, Tollefsen SE, Kornfeld S. The cation-independent mannose 6-phosphate receptor binds insulin-like growth factor II. J Biol Chem. 1988;263:2585-8.

71. MacDonald RG, Pfeffer SR, Coussens L, Tepper MA, Brocklebank CM, Mole JE, et al. A single receptor binds both insulin-like growth factor II and mannose-6-phosphate. Science. 1988;239:1134-7.

72. de Bleser PJ, Jannes P, van Buul-Offers SC, Hoogerbrugge CM, van Schravendijk CF, Niki T, et al. Insulinlike growth factor-II/mannose 6phosphate receptor is expressed on CCl4-exposed rat fat-storing cells and facilitates activation of latent transforming growth factor-beta in cocultures with sinusoidal endothelial cells. Hepatology. 1995;21:1429-37.

73. Greupink R, Bakker HI, van Goor H, de Borst MH, Beljaars L, Poelstra K. Mannose-6-phosphate/insulin-like growth factor-II receptors may represent a target for the selective delivery of mycophenolic acid to fibrogenic cells. Pharm Res. 2006;23:1827-34.

74. Dennis PA, Rifkin DB. Cellular activation of latent transforming growth factor beta requires binding to the cation-independent mannose 6-phosphate/ insulin-like growth factor type II receptor. Proc Natl Acad Sci U S A. 1991;88: 580-4.

75. Beljaars L, Molema G, Weert B, Bonnema H, Olinga P, Groothuis GM, et al. Albumin modified with mannose 6-phosphate: a potential carrier for selective delivery of antifibrotic drugs to rat and human hepatic stellate cells. Hepatology. 1999;29:1486-93.

76. Greupink R, Bakker HI, Bouma W, Reker-Smit C, Meijer DK, Beljaars L, et al. The antiproliferative drug doxorubicin inhibits liver fibrosis in bile ductligated rats and can be selectively delivered to hepatic stellate cells in vivo. J Pharmacol Exp Ther. 2006;317:514-21.

77. Gonzalo T, Beljaars L, van de Bovenkamp M, Temming K, van Loenen AM, Reker-Smit C, et al. Local inhibition of liver fibrosis by specific delivery of a platelet-derived growth factor kinase inhibitor to hepatic stellate cells. J Pharmacol Exp Ther. 2007;321:856-65.

78. Hagens WI, Beljaars L, Mann DA, Wright MC, Julien B, Lotersztajn S, et al. Cellular targeting of the apoptosis-inducing compound gliotoxin to fibrotic rat livers. J Pharmacol Exp Ther. 2008;324:902-10.

79. Moreno M, Gonzalo T, Kok RJ, Sancho-Bru P, van Beuge M, Swart J, et al. Reduction of advanced liver fibrosis by short-term targeted delivery of an angiotensin receptor blocker to hepatic stellate cells in rats. Hepatology. 2010;51:942-52. 
80. Vidil C, Morère A, Garcia M, Barragan V, Hamdaoui B, Rochefort H, et al. Synthesis and biological activity of phosphonate analogs of mannose 6phosphate (M6P). Eur J Org Chem. 1999;1999:447-50.

81. Berkowitz DB, Maiti G, Charette BD, Dreis CD, MacDonald RG. Mono- and bivalent ligands bearing mannose 6-phosphate (M6P) surrogates: targeting the M6P/insulin-like growth factor II receptor. Org Lett. 2004;6:4921-4.

82. Jeanjean A, Garcia M, Leydet A, Montero JL, Morere A. Synthesis and receptor binding affinity of carboxylate analogues of the mannose 6phosphate recognition marker. Bioorg Med Chem. 2006;14:3575-82.

83. Gary-Bobo M, Nirde P, Jeanjean A, Morere A, Garcia M. Mannose 6-phosphate receptor targeting and its applications in human diseases. Curr Med Chem. 2007;14:2945-53.

84. Fitzgerald J, Rich C, Zhou FH, Hansen U. Three novel collagen VI chains, alpha4(VI), alpha5(VI), and alpha6(VI). J Biol Chem. 2008;283:20170-80.

85. Engvall $\mathrm{E}$, Hessle $\mathrm{H}$, Klier G. Molecular assembly, secretion, and matrix deposition of type VI collagen. J Cell Biol. 1986;102:703-10.

86. Mak KM, Sehgal P, Harris CK. Type VI collagen: its biology and value as a biomarker of hepatic fibrosis. Austin Biomark Diagn. 2014;1:1-9.

87. Loreal O, Clement B, Schuppan D, Rescan PY, Rissel M, Guillouzo A. Distribution and cellular origin of collagen VI during development and in cirrhosis. Gastroenterology. 1992;102:980-7.

88. Schuppan D, Ruhlmann T, Hahn EG. Radioimmunoassay for human type VI collagen and its application to tissue and body fluids. Anal Biochem. 1985; 149:238-47.

89. Takahara T, Sollberg S, Muona P, Uitto J. Type VI collagen gene expression in experimental liver fibrosis: quantitation and spatial distribution of mRNAs, and immunodetection of the protein. Liver. 1995;15:78-86.

90. Aumailley M, Specks U, Timpl R. Cell adhesion to type-VI collagen. Biochem Soc Trans. 1991;19:843-7.

91. Pfaff M, Aumailley M, Specks U, Knolle J, Zerwes HG, Timpl R. Integrin and Arg-Gly-Asp dependence of cell adhesion to the native and unfolded triple helix of collagen type VI. Exp Cell Res. 1993;206:167-76.

92. Wayner EA, Carter WG. Identification of multiple cell adhesion receptors for collagen and fibronectin in human fibrosarcoma cells possessing unique alpha and common beta subunits. J Cell Biol. 1987;105:1873-84.

93. Burg MA, Tillet E, Timpl R, Stallcup WB. Binding of the NG2 proteoglycan to type VI collagen and other extracellular matrix molecules. J Biol Chem. 1996; 271:26110-6.

94. Nishiyama A, Stallcup WB. Expression of NG2 proteoglycan causes retention of type VI collagen on the cell surface. Mol Biol Cell. 1993;4:1097-108.

95. Stallcup WB, Dahlin K, Healy P. Interaction of the NG2 chondroitin sulfate proteoglycan with type VI collagen. J Cell Biol. 1990;111:3177-88.

96. Marcelino J, McDevitt CA. Attachment of articular cartilage chondrocytes to the tissue form of type VI collagen. Biochim Biophys Acta. 1995;1249:180-8.

97. Beljaars L, Molema G, Schuppan D, Geerts A, De Bleser PJ, Weert B, et al. Successful targeting to rat hepatic stellate cells using albumin modified with cyclic peptides that recognize the collagen type VI receptor. J Biol Chem. 2000;275:12743-51.

98. Du SL, Pan H, Lu WY, Wang J, Wu J, Wang JY. Cyclic Arg-Gly-Asp peptidelabeled liposomes for targeting drug therapy of hepatic fibrosis in rats. J Pharmacol Exp Ther. 2007;322:560-8.

99. Li F, Sun JY, Wang JY, Du SL, Lu WY, Liu M, et al. Effect of hepatocyte growth factor encapsulated in targeted liposomes on liver cirrhosis. J Control Release. 2008;131:77-82.

100. Bonner JC. Regulation of PDGF and its receptors in fibrotic diseases. Cytokine Growth Factor Rev. 2004;15:255-73.

101. Fredriksson L, Li H, Eriksson U. The PDGF family: four gene products form five dimeric isoforms. Cytokine Growth Factor Rev. 2004;15:197-204.

102. Wong L, Yamasaki G, Johnson RJ, Friedman SL. Induction of beta-plateletderived growth factor receptor in rat hepatic lipocytes during cellular activation in vivo and in culture. J Clin Invest. 1994;94:1563-9.

103. Pinzani M, Milani S, Herbst H, DeFranco R, Grappone C, Gentilini A et al. Expression of platelet-derived growth factor and its receptors in normal human liver and during active hepatic fibrogenesis. Am J Pathol. 1996;148:785-800.

104. Clements JM, Bawden LJ, Bloxidge RE, Catlin G, Cook AL, Craig S, et al. Two PDGF-B chain residues, arginine 27 and isoleucine 30 , mediate receptor binding and activation. EMBO J. 1991;10:4113-20.

105. Beljaars L, Weert B, Geerts A, Meijer DK, Poelstra K. The preferential homing of a platelet derived growth factor receptor-recognizing macromolecule to fibroblast-like cells in fibrotic tissue. Biochem Pharmacol. 2003;66:1307-17.
106. Hagens WI, Mattos A, Greupink R, de Jager-Krikken A, Reker-Smit C, van Loenen-Weemaes A, et al. Targeting 15d-prostaglandin $J 2$ to hepatic stellate cells: two options evaluated. Pharm Res. 2007;24:566-74.

107. Li F, Li QH, Wang JY, Zhan CY, Xie C, Lu WY. Effects of interferon-gamma liposomes targeted to platelet-derived growth factor receptor-beta on hepatic fibrosis in rats. J Control Release. 2012;159:261-70.

108. Li Q, Yan Z, Li F, Lu W, Wang J, Guo C. The improving effects on hepatic fibrosis of interferon-gamma liposomes targeted to hepatic stellate cells. Nanotechnology. 2012;23:265101.

109. Engstrom U, Engstrom A, Ernlund A, Westermark B, Heldin CH. Identification of a peptide antagonist for platelet-derived growth factor. J Biol Chem. 1992;267:16581-7.

110. Brennand DM, Dennehy U, Ellis V, Scully MF, Tripathi $P$, Kakkar W, et al. Identification of a cyclic peptide inhibitor of platelet-derived growth factor-BB receptor-binding and mitogen-induced DNA synthesis in human fibroblasts. FEBS Lett. 1997:413:70-4.

111. Brennand DM, Scully MF, Kakkar W, Patel G. A cyclic peptide analogue of loop III of PDGF-BB causes apoptosis in human fibroblasts. FEBS Lett. 1997; 419:166-70.

112. Kreysing J, Ostman A, van de Poll M, Backstrom G, Heldin CH. Identification of three amino acid residues in the B-chain of platelet-derived growth factor with different importance for binding to PDGF alpha- and betareceptors. FEBS Lett. 1996;385:181-4

113. Camorani S, Esposito CL, Rienzo A, Catuogno S, laboni M, Condorelli G, et al. Inhibition of receptor signaling and of glioblastoma-derived tumor growth by a novel PDGFRbeta aptamer. Mol Ther. 2014;22:828-41.

114. Gambhir SS. Molecular imaging of cancer with positron emission tomography. Nat Rev Cancer. 2002;2:683-93.

115. Paefgen V, Doleschel D, Kiessling F. Evolution of contrast agents for ultrasound imaging and ultrasound-mediated drug delivery. Front Pharmacol. 2015:6:197.

116. Kang N, Gores GJ, Shah VH. Hepatic stellate cells: partners in crime for liver metastases? Hepatology. 2011;54:707-13.

117. Coulouarn C, Clement B. Stellate cells and the development of liver cancer: therapeutic potential of targeting the stroma. J Hepatol. 2014;60:1306-9.

\section{Submit your manuscript to a SpringerOpen ${ }^{\odot}$ journal and benefit from:}

- Convenient online submission

- Rigorous peer review

- Immediate publication on acceptance

- Open access: articles freely available online

- High visibility within the field

- Retaining the copyright to your article

Submit your next manuscript at $>$ springeropen.com 